\title{
Analysis of MaACS2, a stress-inducible ACC Synthase Gene in Musa acuminata AAA Group Cultivar Pisang Ambon
}

\author{
Resnanti Utami Handayani \& Fenny M. Dwivany* \\ School of Life Sciences and Technology, Institut Teknologi Bandung \\ Jalan Ganesha No. 10 Bandung 40132 Indonesia \\ E-mail: fenny@sith.itb.ac.id
}

\begin{abstract}
Ethylene has an important function in plant growth and development. Ethylene production generally increases in response to pathogen attacks and other environmental stress conditions. The synthesis of this phytohormone is regulated by two enzymes, ACC synthase (ACS) and ACC oxidase (ACO). ACC synthase is encoded by a multigene that regulates the production of ACC, after which this precursor is converted into ethylene by ACO. Pisang Ambon (Musa sp. AAA group), a banana cultivar originating from Indonesia, has nine ACS genes (MaACS 1-9) and one ACO gene (MaACO). One of the banana ACS genes, MaACS2, is stress-inducible. In this research, we have investigated the expression profile of MaACS2 in the roots and leaf tissues of infected tissue culture plants. Quantification of gene expression was analyzed using Real-Time PCR (qPCR) using Ma18srRNA and MaGAPDH as reference genes. The results showed nine-to ten fold higher MaACS2 expression levels in the infected roots tissues compared to the uninfected roots tissues. However, MaACS2 expression in the leaves was only detected in infected tissue.
\end{abstract}

Keywords: banana; environmental stress; ethylene; MaACS2; Real-Time PCR (qPCR).

\section{Introduction}

Ethylene is formed from methionine to 1-aminocyclopropane-1-carboxylic acid (ACC) by the action of ACC synthase (ACS), and the conversion of ACC to ethylene is carried out by ACC oxidase (ACO) [1]. ACC synthase is considered to be the rate-limiting step in ethylene synthesis [2]. ACC synthase and ACC oxidase are encoded by $A C S$ and $A C O$ respectively. The expression of these genes is differentially regulated by various developmental, environmental and hormonal signals. Many abiotic stress conditions, including chilling and freezing, high temperature, flooding, drought, chemical damage, radiation, and mechanical perturbation, can also stimulate ethylene production. High levels of ethylene production can in turn inhibit growth, cause premature ripening and induce the onset of senescence, which then potentially reduces plant productivity.

Received Oktober $25^{\text {th }}, 2013$, Revised May 14 ${ }^{\text {th }}, 2014$, Accepted for publication August $22^{\text {nd }}, 2014$.

Copyright (C) 2014 Published by ITB Journal Publisher, ISSN: 2337-5760, DOI: 10.5614/j.math.fund.sci.2014.46.2.8 
It is known that ACS is encoded by a multi-gene family. ACS is the ratelimiting step in biosynthesis of ethylene. It is a limiting factor of 1aminocyclopropane-1-carboxylic acid (ACC) production. Therefore, the study of $A C S$ expression has become a priority in studying ethylene biosynthesis. Karmawan, et al. [3] have identified nine ACS genes (MaACS1-9) from Pisang Ambon leaves from tissue culture. Huang, et al. [4] have isolated and analyzed the expression of the MaACS gene family from banana peel during the ripening process and exogenous ethylene treatment [4].

Environmental factors such as abiotic and biotic stress are known as inducible factors for ethylene biosynthesis in plants [5]. Abiotic factors such as water logging can accumulate ACC in tomato roots and then transport it to the leaves and convert the ACC into ethylene [6]. For example, it has been reported that environmental stress such as flooding could affect LeACS3 gene expression in tomatoes. Olson, et al. [7] have shown that the LeACS3 gene was expressed in the roots part of a tomato plant in response to flooding stress. While in a study about cotton has reported that wounding, $\mathrm{ABA}$, and $\mathrm{Cu}^{2+}$ play a role in the regulation of GhACS1 gene expression [8].

The effect of biotic factors such as fungi on ethylene production has also been studied. Ecker and Davis [9] have stated that fungal pathogens and elicitors can induce ethylene biosynthesis in plants. Wounding caused by a pathogen attack is one of the key factors in inducing ripening-associated genes and ethylene production. For example, black rot fungus (Ceratocystis fimbriata Ell. \& Halst) can increase the production of ethylene in the root tissue of Ipomoea batatas [10].

There is little information about pathogen effects on banana MaACS2 gene expression. In this study, we have investigated the MaACS2 expression profile in the roots and leaves of banana plant that were infected with pathogens. We used Pisang Ambon, a banana cultivar originally from Indonesia

\section{$2 \quad$ Materials and Methods}

\subsection{Plant Materials}

Vegetative tissues (leaves and roots) were collected from banana plantlets in vitro. Samples were collected from uninfected (control) and infected (by fungus/microbe) plants, and frozen in liquid nitrogen for further analysis. 


\subsection{RNA Isolation, RT-PCR, Cloning and Sequencing}

Total RNA was extracted from leaves and roots using the method from Liu, et al. [11] with some modifications. We modified the protocol to optimize the quantity of extracted RNA by pre-heating the buffer at $65^{\circ} \mathrm{C}$ and also incubated the pulverized tissue on the buffer for an hour at $65^{\circ} \mathrm{C}$, mixing it well by spinning every 15 minutes. The detailed procedures were as follows. About $4 \mathrm{~g}$ of tissue was pulverized in the presence of liquid nitrogen on pre-cooled mortar and pestle. The frozen powder was then transferred into a $50 \mathrm{~mL}$ polypropylene centrifuge tub econtaining pre-heated extraction buffer $[100 \mathrm{mM}$ TrisHCl $(\mathrm{pH}$ 7.5); $500 \mathrm{mM} \mathrm{NaCl} ; 25 \mathrm{mM}$ EDTA (pH 8.0); 1.5\% SDS; 2\% PVP (MW 40.000) and $0.7 \%$ of 2-mercaptoethanol]. The tubes were then incubated at $65^{\circ} \mathrm{C}$ for 1 hour and vortexed for 15 minutes every 15 minutes at room temperature. The supernatant was then transferred into a fresh tube, added with $1 / 3$ volume of $5 \mathrm{M}$ potassium acetate ( $\mathrm{pH}$ 6.0), mixed well and incubated on ice for 30 minutes. The suspension was spun for 15 minutes at $4^{\circ} \mathrm{C}$. The supernatant was then transferred into a new tube, extracted with an equal volume of phenol/ chloroform/isoamyl alcohol and mixed by inverting the tubes several times. The phenol and aqueous phase were separated by spinning for 10 minutes at $4^{\circ} \mathrm{C}$. Two extractions were usually required to obtain a debris-free interface between phases. These procedures were then followed by extracting the aqueous phase once with an equal volume of chloroform/isoamyl alcohol. The RNA pellet was then precipitated by ethanol absolute, washed by $70 \%$ ethanol and air dried. The RNA was then dissolved in DEPC water and stored at $-80^{\circ} \mathrm{C}$. RNA yield and purity were checked by means of UV absorption spectra, while RNA integrity was ascertained by electrophoresis on agarose gel followed by ethidium bromide staining.

The isolated RNA was used as a template for cDNA synthesis. cDNA was prepared by reverse-transcriptation from extracted RNA as a template using an iScript $^{\mathrm{TM}}$ cDNA Synthesis Kit (BioRad, Catalogue No. 170-8890). Specific primers were used to isolate and amplify the cDNA fragments of MaACS2 and two housekeeping genes, MaGADPH and Mal8srRNA. The primer pair to amplify MaGADPH (Accession No. AY821550) were $M a G A D P H \_F$ 5'-TCAA CGACCCCTTCATCAC-3' and MaGADPH_R 5'-AGCAGCCTTGTCCTTGT CA-3', while the primer pair for MaACS2 (Accession No. AF056162) were $M a A C S 2$ F 5'-CTTGAGAACCATCCCGACC-3' and MaACS2_R 5'-TCATT GGCAGAAGTAGCACC-3'. Both primer pairs were obtained from previous research [3]. The Mal8srRNA primer pair was designed based on the conserved region from several banana species. The primer sequences were Ma18srRNA_F 5'-CGAGGGGATGAACTACCAA-3' and Ma18srRNA_R5'-TATCCGTTGC $\bar{C}$ GAGAGTC-3'. 
GoTaq $^{\circledR}$ Green Master Mix (Promega, Catalogue No. M7122) was used for the PCR reaction, using the Thermal Cycler GeneAmp PCR System 2400 (Applied Biosystems ${ }^{\circledR}$ ). The amplification reactions were initially held at $94^{\circ} \mathrm{C}$ for $2 \mathrm{~min}$, then $94^{\circ} \mathrm{C}$ for $30 \mathrm{~s}, 48.5^{\circ} \mathrm{C}$ for $30 \mathrm{~s}$ (for $\mathrm{MaGAPDH}$ and $\mathrm{MaACS} 2$ ) or $50.5^{\circ} \mathrm{C}$ for $30 \mathrm{~s}(M a 18 s r R N A)$ and $72^{\circ} \mathrm{C}$ for $30 \mathrm{~s}$, with a final period of $72^{\circ} \mathrm{C}$ for $7 \mathrm{~min}$. The cDNA was then cloned into cloning vector pGEM $^{\mathbb{B}}$-T Easy from PROMEGA (Catalogue No. A1360) using T4 DNA Ligase and transformed into the competent cell of Eschericia coli strain DH5a. The insert of the cDNA in vector pGEM $^{\circledR}$-T Easy was confirmed by PCR (using specific primers SP6/T7 which flanked the cDNAinsert in the vector) and endonuclease restriction (using $E c o R I$ enzyme). The nucleotide sequences of the cDNA inserts were determined by the sequencing service from MACROGEN-KOREA.

\subsection{Quantification of MaACS2 Transcript by Real-Time PCR}

The accumulation levels of theMaACS2 transcripts were analyzed by real-time PCR. iQ SYBR Green Supermix (BioRad, Catalogue No. 170-8880) was used as a dye for all qPCR experiments, following the manufacturer's protocol. Melting curve analysis was performed to check for primer dimer formation and non-specific amplification using the CFX Real-Time PCR detection system (BioRad). The variation in expression levels for all control genes was calculated using geNorm (allserv.urgent.be/ jvdesomp/genorm) and the normalization factor was calculated based on the geometric mean of the two control genes.

\section{$3 \quad$ Results and Discussion}

The morphology of the two banana cultures (infected roots and uninfected roots) was slightly different. The infected roots formed more adventitious roots than the uninfected roots (Figure 1). It has been reviewed in Kuroha and Satoh [12] that when ethylene biosynthesis is induced by wounding, then ethylene could stimulate adventitious root formation.

The total RNA from each banana culture was isolated for further analysis. The method from Liu, et al. [11] was used for extracting RNA from the banana leaves and roots. The integrity of the isolated RNA was checked by electrophoresis on $1.5 \%(\mathrm{w} / \mathrm{v})$ agarose gels containing formaldehyde (Figure 2). The concentration of total RNA samples isolated from vegetative samples was about $0.5-1 \mu \mathrm{g} / \mu \mathrm{L}$ with a ratio of $\left(\lambda_{260 / 280}\right) 1.333$ to 1.720 . About $50 \mu \mathrm{g} / \mathrm{mL}$ of total RNA from banana vegetative tissues was used as a template for cDNA synthesis using reverse-transcriptase and amplified using specific primers by PCR. 


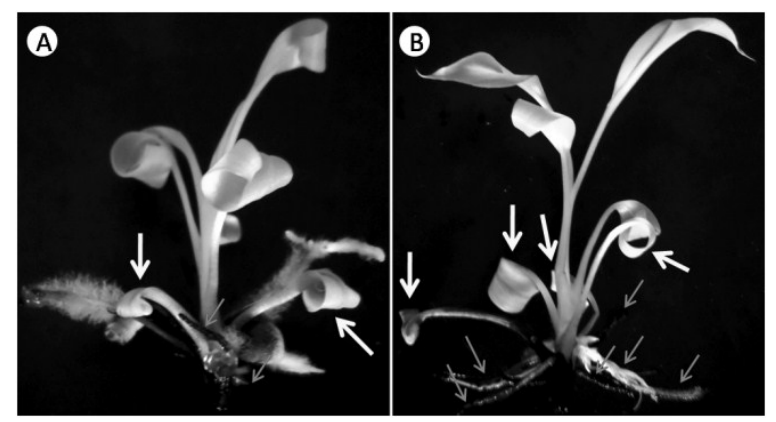

Figure 1 Banana cultures used for RNA isolation: (a) culture with uninfected roots, (b) culture with infected roots. Thin arrows indicate adventitious roots. Leaf chlorosis on the banana leaves is indicated by bold arrows.

The MaACS2 (GQ406066.1) from Pisang Ambon that was used in this study has been isolated by Karmawan, et al. [3]. It had $100 \%$ similarity with the GMACS-1 gene from Musa acuminate (AAA group) cultivar Hsien Jin Chiao (AF056162) and the MA-ACS2 gene (AB021907.1) from M. acuminata (AAA group) cultivar Cavendish Grand Nain (data not shown). The MaACS2 gene expression profile from each sample was determined using qPCR. Quantification of all gene expressions from all samples was performed using SYBR Green as fluorescence dye. Melting curve analysis was done to check for primer dimer formation and specificity of the primers. The melting curve showed a single peak, meaning that there was no dimer or unspecific amplification (data not shown). In the qPCR analysis, two reference genes were used for normalization. Normalizing to an endogenous reference is a common method for correcting different amounts of input cDNA [13]. Vandesompele, et al. [14] suggest that at least two or three housekeeping genes are needed for normalization. Therefore, two internal genes, MaGADPH and Mal8srRNA were used in this research as reference genes.

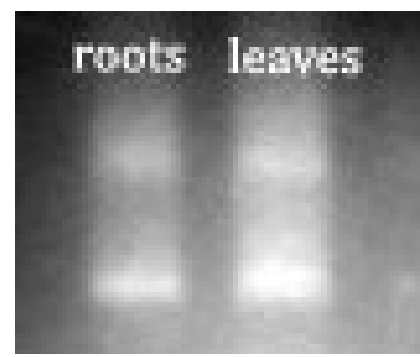

Figure 2 Electrophoregram of RNA isolated from banana root and leaf tissue (agarose 1.5\%). 
The qPCR results (Figure 3) showed that the expression profiles of MaACS2 in infected tissue and uninfected tissue were different. It appears that the expression of MaACS2 was induced by stress signal, particularly by wounding, which caused by a biotic factor (fungi/microbe) in the infected tissues. The infected tissues had a much higher expression of MaACS2 than the uninfected tissues, especially those of the roots. The MaACS2 levels in the infected roots were much higher than in the uninfected roots tissues, i.e. nine- to tenfold higher. In the leaf tissues, the MaACS2 gene was only expressed in the infected tissues.

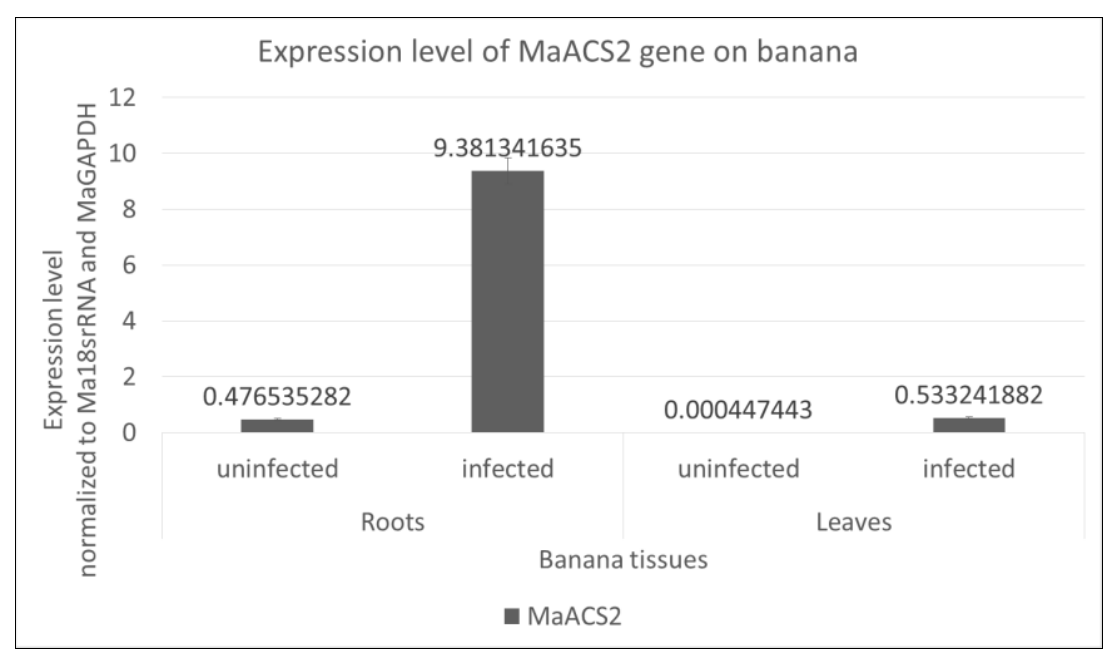

Figure 3 MaACS2 gene expression level in banana infected and uninfected vegetative tissues.

Based on Liu, et al. [15], and Hubert and Mbéguié-A-Mbéguié [16], MaACS2 is involved in ethylene biosynthesis, which in turn is induced by wounding. In addition, $\mathrm{Li}$, et al. [17] have reported that wounding in tomatoes results in an increase of the ACC synthase transcript level. The experiment by Li, et al. [17] also showed that a wound-inducible transcript may also developmentally regulate, therefore gene expression is also present in the leaves, stem and roots of the tomato plant at a lower level. In this study, MaACS2 regulation in the roots and leaves may be similar to that case, since ethylene is known to be synthesized by plant during vegetative development.

Normally, ethylene is also involved in the plant development process and the response to stress [18]. Ethylene acts as a positive regulator of root and root hair formation [19]. It has also been reported that ethylene has a role in adventitious root development in deep-water rice [20-22]. 
It appears that in the infected banana culture, the activation of the MaACS2 gene in response to biotic stress factors may enhance the synthesis of ACC, an ethylene precursor. Then the ACC, together with auxin, may cause inhibition of root elongation while initiating the formation of adventitious roots. It has been reported that auxin and ACC inhibit root elongation [23-25]. Another report has shown that adventitious root formation was induced by ethylene but not by auxin, giberrelin, and cytokinin [20]. It is also expected that if the expression of the MaACS2 gene would synthesize more ACC, then the ACC would be converted to ethylene. Both ACC and ethylene then may have roles in the formation of adventitious roots.

Different from its expression in the roots, MaACS2 was only expressed in the infected leaves and not in the uninfected ones. Some senescent leaves were observed in the infected cultures. It has been reviewed by Dolan [26] that in tomato plants, the ACC is soluble in water and can move through apoplast over a great distance (from roots to shoots). Research done by Bradford and Yang determined that ACC, an ethylene precursor, was produced rapidly in the roots during anaerobic stress conditions due to flooding, because there was an increase of ACC synthase transcription and enzymatic activity in the roots [6]. Then, when oxygen was present in the aerial parts, especially the leaves, the transported ACC was converted into ethylene by ACC oxidase, causing epinasty. Hogan, et al. [27] confirmed in their study that in hydroponicallygrown strawberry plants, ethylene production in the strawberry leaves increased following hypoxia in the roots. In this study, it could be explained why the infected tissues expressed a higher level of MaACS2 in the roots and also in the leaves than in the uninfected tissues, namely because the infected roots may synthesize a high amount of ACC and then transport it to the leaf parts, which then may induce ethylene production and cause leaf senescence.

\section{Conclusion}

The results described in this study showed that MaACS2 gene was actively transcribed on the pathogen-infected roots and leaves tissue. Apparently, $M a A C S 2$ gene also could be detected on the non-infected tissues, however the level were significantly different with the infected ones. Taiz and Zeiger [19] stated that the "elimination of ethylene responsiveness will prevent the development of disease symptoms, even though the growth of the pathogen appears to be unaffected". However, ethylene also required in a combination with jasmonic acid to activates several plant defensive genes. Therefore, regulating the rate of ethylene biosynthesis regarding pathogen attack is important to achieve plant pathogenic resistant. This study has shown that $M a A C S 2$ is a good candidate gene to be regulated for that purpose. Further studies can be conducted to develop a transgenic plant which has ability to 
adapt on environmental stress conditions, such as flooding, drought, mechanical stress, pathogen attack, etc. For example, the MaACS2 gene promoter can be used as an alternative inducible promoter for development of new transgenic plants. Further analysis on MaACS2 gene and promoter are needed to obtain full information about this gene, especially its regulations and specificity. Then in the future, it can be provided as a new effective tool for the development of transgenic plants, especially for the improvement of new plants which resistant to pathogen attacks and other environmental stresses.

\section{Acknowledgements}

This research was funded by PT. Indofood Sukses Makmur, Tbk through the Indofood Riset Nugraha 2008 program.

\section{References}

[1] Kende, H., Ethylene Biosynthesis, Annual Review Plant Physiology \& Plant Molecular Biology, 44, pp. 283-307, 1993.

[2] Yamagami, T., Tsuchisaka, A., Yamada, K., Haddon, W.F., Harden, L.A. \& Theologis, A., Biochemical Diversity among the 1Aminocyclopropane-1-Carboxylate Synthase Isozymes Encoded by the Arabidopsis Gene Family, Journal of Biological Chemistry, 278, pp. 49102-49112, 2003.

[3] Karmawan, L.U., Suhandono, S. \& Dwivany, F.M., Isolation of MAACS Gene Family and Expression Study of MA-ACS1 Gene in Musa acuminate Cultivar Pisang Ambon Lumut, HAYATI Journal of Biosciences, 3, pp. 35-39, 2009.

[4] Huang, F.C., Yi, Y.D.\& Huang, P.L., Genomic Organization of a Diverse ACC Synthase Gene Family in Banana and Expression Characteristics of the Gene Member Involved in Ripening of Banana Fruits, Journal of Agricultural and Food Chemistry, 54, pp. 3859-3868, 2006.

[5] Hall, M.A. \& Smith, A.R., Ethylene and the Responses of Plants to Stress, Bulgarian Journal of Plant Physiology, 21(2-3), pp. 71-79, 1995.

[6] Bradford, K.J. \& Yang, S.F., Stress-Induced Ethylene Production in the Ethylene-Requiring Tomato Mutant Diageotropica, Plant Physiology, 65, pp. 327-330, 1980.

[7] Olson, D.C., Oetiker, J.H. \& Yang, S.F., Analysis of LE-ACS3, A 1Aminocyclopropane-1-Carboxylic Acid Synthase Gene Expressed during Flooding in the Roots of Tomato Plants, Journal of Biological Chemistry, 270(23), pp. 14046-14061, 1995.

[8] Wang, X., Zhang, Y., Zhang, J., Cheng, C. \& Guo, X., Molecular Characterization of a Transient Expression Gene Encoding for 1Aminocyclopropane-1-carboxylate Synthase in Cotton 
(Gossypiumhirsutum L.), Journal of Biochemistry and Molecular Biology, 40(5), pp. 791-800, 2007.

[9] Ecker, J.R. \& Davis, R.W., Plant Defense Gene are Regulated by Ethylene, Proceeding of National Academy of Science, 84, pp. 52025206, 1987.

[10] Hyodo, H., Yoshioka, S., Imai, Y., Nakane, H. \& Nishikawa, F., Ethylene Biosynthesis in Sweet-Potato Root Tissue Induced by Infection with Black Rot Fungus (Ceratocystisfimbriata), Botany Bulletin Academy Sin, 44, pp. 179-186, 2003.

[11] Liu, J., Goh, C., Loh, C., Liu, P. \& Pua, E., A Method for Isolation of Total RNA from Fruit Tissues of Banana, Plant Molecular Biology Reporter, 16, pp. 1-6, 1998.

[12] Kuroha, T. \& Satoh, S. Involvement of Cytokininsin Adventitious and Lateral Root Formation, Plant Root, 1, pp. 27-33, 2007.

[13] Livak, K.J. \& Schmittgen, T.D., Analysis of Relative Gene Expression Data using Real-Time Quantitative PCR and the $2^{-\Delta \Delta C T}$ Method, Methods, 25, pp. 402-208, 2001.

[14] Vandesompele, J., Preter, K. D., Pattyn, F., Poppe, B., Van Roy, N., Paepe A.D. \& Speleman, F., Accurate Normalization of Real-Time Quantitative RT-PCR Data by Geometric Averaging of Multiple Internal Control Genes, Genome Biology, 3(7), 2002.

[15] Liu, X., Shiomi, S., Nakatsuka, A., Kubo, Y., Nakamura, R. \&Inaba, A., Characterization of Ethylene Biosynthesis Associated with Ripeningin Banana Fruit, Plant Physiology, 121, pp. 1257-1265, 1999.

[16] Hubert, O. \& Mbéguié-A-Mbéguié, D., Expression Patterns of Ethylene Biosynthesis Genes from Bananas During Fruit Ripening and in Relationship with Finger Drop, AoB Plants, 2012, pls041, 2012. (doi: 10.1093/aobpla/pls041)

[17] Li, N., Parsons, B.L., Liu, D. \& Mattoo, A.K., Accumulation of WoundInducible ACC Synthase Transcript in Tomato Fruit is Inhibited by Salicylic Acid and Polyamines, Plant Molecular Biology, 18, pp. 477487, 1992.

[18] Deikman, J., Molecular Mechanisms of Ethylene Regulation of Gene Transcription, Plant Physiology, 100, pp. 561-566, 1997.

[19] Taiz, L. \& Zeiger, E., Plant Physiology, $3^{\text {rd }}$ ed., Sunderland, Massachusetts: Sinauer Associates, Inc., 2002.

[20] Lorbiecke, R. \& Sauter, M., Adventitious Root Growth and Cell-Cycle Induction in Deepwater Rice, Plant Physiology, 119, pp. 21-29, 1999.

[21] Steffens, B., Wang, J. \& Sauter, M., Interactions between Ethylene, Gibberellin and Abscisic Acid Regulate Emergence and Growth Rate of Adventitious Roots in Deepwater Rice, Planta, 22, pp. 604-612, 2006.

[22] Visser, E., Cohen, J.D., Barendse, G., Blom, C. \& Voesenek, L., An Ethylene-Mediated Increase in Sensitivity to Auxin Induces Adventitious 
Root Formation in Flooded Rumex Palustris Sm., Plant Physiology, 112, pp. 1687-1692, 1996.

[23] Ivanchenko, M.G., Muday, G.K \& Dubrovsky, J.G., Ethylene-auxin Interactions Regulate Lateral Root Initiation and Emergence in Arabidopsis thaliana, The Plant Journal, 55, pp. 335-347, 2008.

[24] Stepanova, A.N., Yun, J., Likhacheva, A.V. \& Alonso, J.M., Multilevel Interactions between Ethylene and Auxin in Arabidopsis Roots, Plant Cell, 19, pp. 2169-2185, 2007.

[25] Swarup, R., Perry, P., Hagenbeek, D., Van Der Straeten, D., Beemster, G.T., Sandberg, G., Bhalerao, R., Ljung, K. \& Bennett, M.J., Ethylene Upregulates Auxin Biosynthesis in Arabidopsis Seedlings to Enhance Inhibition of Root Cell Elongation, Plant Cell, 19, pp. 2186-2196, 2007.

[26] Dolan, L., The Role of Ethylene in the Development of Plant Form, Journal of Experimental Botany, 48(207), pp. 201-210, 1997.

[27] Hogan, J.D., Murray, E.E. \& Harrison, M.A., Ethylene Production as an Indicator of Stress Conditions in Hydroponically-Grown Strawberries, Scientia Horticulturae, 110, pp. 311-318, 2006. 